\title{
Los indios, los jesuitas y el Mercosur
}

\author{
Augusto Jaeger Junior
}

Abogado, graduado por la Facultad de Derecho de Santo Angelo, con titulo de posgrado de la misma facultad y master en Derecho Internacional de la UFSC. Profesor de la Universidad Regional Integrada do Alto Uruguai e das Missöes y de la Universidad do Oeste de Santa Catarina, en las cátedras de Derecho Internacional, Derecho Provisional y Derecho Civil. Es autor de diversos articulos para revistas sobre el MERCOSUR.

SUMARIO: I. Introducción. - II. La semilla de la idea de integración. - III. La contribución de la historia sudamericana a la actual integración de los pueblos. - IV. El surgimiento del MERCOSUR. - V. Consideración final. - VI. Referencias bibliográficas.

\section{INTRODUCCIÓN}

El presente artículo busca presentar la contribución de la Historia, recogida desde el descubrimiento de América, para lograr una mejor comprensión del actual proceso de integración en curso entre los países integrantes del MERCOSUR. Aunque sea abogado por formación, en la actualidad estoy abocado a la investigación de muchos aspectos de la historia de América del Sur y he encontrado consideraciones relevantes acerca del pueblo que habría desarrollado una suerte de integración: me refiero a los indios, primeros habitantes de estas tierras, auxiliados en su tarea por los jesuitas, que habían llegado para extender su religión.

\section{LA SEMILLA DE LA IDEA DE INTEGRACIÓN}

La idea de integración de los pueblos es muy antigua. Hace dos mil años, los cristianos ya aspiraban a un mundo unido por la fe y por el cristianismo. Los romanos querían unir al mundo, incluso por medio del empleo de la fuerza. Napoleón también estuvo cerca de 
concretar su deseo de dominarlo. Hitler quería imponer la belicosidad aria para erguirse en comandante de todos los pueblos, sólo para citar algunos de los intentos de integración nundial en sus respectivas épocas.

Más recientemente, en el campo del Derecho, ya teníamos el ejemplo desde la Segunda Guerra Mundial, cuando se iniciaron los acuerdos hacia la integración regional de Europa con el objeto de lograr la paz mundial y el incremento de la economía. Actualmente la Unión Europea es el mejor ejemplo conocido de integración surgido de aquel período y la base de lo que se pretende para el MERCOSUR.

Sin embargo, debe ser objeto de un debate más profundo la pretensión de los estudiosos del Derecho que piensan que lo que hoy tenemos en términos de integración recién se inició en América con su pacificador Simón Bolívar, en el siglo pasado, o en Europa con Jean Monnet, en este siglo.

III. La contribución de la historia sudamericana a la actual integración de los pueblos

No es que los roles de estos personajes hayan sido irrelevantes, al revés, pero en la Historia surge el relato de que el proyecto de la Compañía de Jesús en América, y especialmente en la Cuenca del Plata, ya tenía rasgos integracionistas, con un lenguaje común, el guaraní, y una religión común, el cristianismo.

Desde el punto de vista político el territorio que hoy abarca el MERCOSUR ya era el blanco de disputas desde la época del interés de Portugal y de España por las tierras ubicadas entre Laguna y Buenos Aires, pasando por la región de los Siete Pueblos de las Misiones y por Colonia del Sacramento, tierras éstas que han cambiado varias veces de dominio en virtud de los sucesivos Tratados de Tordesillas y de Madrid, éste último de 1750. Sus habitantes, los indios, desconocían las fronteras nacionales y habían desarrollado una especie de integración sociocultural suigeneris, auxiliados por los jesuitas que habían llegado para extender su religión.

En lo que atañe a ese tema, Lucía Gálvez, profesora de Historia de la Facultad de Filosofía y Letras de la Universidad de Buenos Aires, a cuyos trabajos he tenido acceso por ocasión de una visita a Montevideo, dice que la idea preveía incluso pacificar la región, fomentar el comercio entre las reducciones, formar milicias guaraníes y proinover el intercambio cultural, especialmente musical y teatral ${ }^{1}$.

De modo tal que los sacerdotes Manuel da Nóbrega y José de Anchieta (que desembarcaron en Brasil en 1549 y 1553, respectivamente) fueron los prineros en aprender el idioma y las costumbres de los tupíes y escribieron, también, gramáticas y catecismos en. guaraní. Mucho después, "En 1700, ya instalada la primera imprenta en Candelaria, se imprimieron varios libros en ese idioma, entre ellos algunos escritos por guaraníes como

${ }^{2}$ GÁLVEZ, Lucía. (1977), "Las misiones entre los guaraníes: primer intento de integración regional", en: CLEMEMTI, Hebe (org), La dimensión cultural del MERCOSUR. Buenos Aires, UBA, p. 45-59. 


\section{Nicolás Yapuguay".}

Fueron las fundiciones de hierro existentes, la fabricación de campanas, anzuelos y cuchillos, los aspectos espirituales de la búsqueda de la Tierra sin Mal y la creencia en el divino Tupá por parte de los guaraníes los principales aspectos que han contribuido para la rápida expansión integracionista.

Esta unidad se encontraba en el centro de una región integracionista que se extendía desde las ciudades actuales de Posadas y Encarnación hasta las Cataratas del Iguazú, y desde Uruguay, explorado por Roque González. Finalmente Roque González, que había hecho una valiosa contribución e incluso había introducido el cultivo de la uva en 1626 en Rio Grande do Sul, en São Nicolau, encontró la muerte en Caaró, en manos de indígenas instigados por un hechicero. Pero el Santo Evangelio sigue predicándose en las reducciones ${ }^{3}$, con el objeto de integrarlas en una gran región.

El idioma común ha permitido la formación de una extensa red de comunicaciones entre las reducciones. La producción de telas de algodón, la cría de ganado vacuno y caballar y el almacenamiento de los excedentes enseñados por los jesuitas han contribuido a la integración también económica, sui generis para la época. Puentes y caminos que abrían los indios facilitaban su libre circulación, que de todas formas era posible por vías fluviales, y hacían de la integración una realidad en toda la Cuenca del Plata.

El campo cultural fue pródigo en integraciones. Los músicos de las reducciones solían desplazarse dentro del territorio para cantar y animar las fiestas que se celebraban en otros pueblos, además de enseñarles el arte a los niños. Muchos, incluso, iban a estudiar en Córdoba y Buenos Aires, donde ya en 1677 habían escuelas bilingües, universidades y talleres gráficos. Según algunos autores, estas escuelas se equiparaban a las de Salamanca y a la propia Sorbona parisina de aquel entonces en Filosofía y 'Teología jesuíticas'.

En la Región de las Misiones, en el estado de Rio Grande do Sul, surge la yerba mate como principal riqueza comercial. Se comerciaba a través de peruanos que verúan a Santa Fe y a Buenos Aires a comprarla, y el dinero de la venta se usaba para fabricar instrumentos musicales, imágenes religiosas e incluso artículos de lujo. Todavía hoy la yerba mate, popularmente conocida como mate, chá-dos-jesuítas, chá-das-missões y otras decenas de denominaciones, también de origen indígena como caá y caút-caati, está íntimamente

\footnotetext{
2Idem. p. 49 (Traducción libre hecha por el autor de este artículo para el presente trabajo).

"Para una mejor comprensión, las reducciones eran pueblos indígenas instalados en sitios que reunían ciertos rasgos geográficos, topográficos y climatológicos, generalmente a las orillas de los ríos y cercanos a otros pueblos, lo que les garantizaba seguridad. La primera se fundó en 1610 y se llamó San Ignacio Guazú, y la última, en 1707, denominada Santo Ângelo. BRUXEL, Arnaldo. (1978), Os trinta povos Guaranis. Caxias do Sul (UCS) - Porto Alegre, Sulina. p. 162.

${ }^{4}$ RUSCHEL, Ruy Ruben. (1998), "Sistema jurídico dos povos missioneiros", en: WOLKMER, Antônio Carlos (org.), Direito e justiça na América indúgena: da conquista à colonização. Porto Alegre, Livraria do Advogado, p. 95-109.
} 
relacionada al gaucho por medio del cimarrón, su bebida tradicional.

En ese momento la acción devastadora de los bandeirantes portugueses en busca de esclavos, iniciada en 1628, amenazó la integración regional. El sentimiento de integración de los indígenas los hizo intentar una reacción conjunta en contra de aquella agresión.

También en 1756, herido por un lanzazo de un dragón portugués y por un tiro de pistola del general español José Viana, moría el jefe guaraní Sepé Tiaraju, en territorio de la actual São Gabriel.5.

Como se observa, los indios no conocían fronteras. Llegaban desde Perú a Argentina, trasponiendo barreras naturales como montes, ríos, valles, bañados y a otros enemigos. El actual estado de Rio Grande do Sul albergaba reducciones y era, inclusive, una especie de centro geográfico de paso de los que se dirigían hacia Montevideo y Buenos Aires. Allí la civilización indígena contaba con una reducción preemiente, São Miguel das Missões, que desde 1983 es patrimonio histórico de la humanidad y cuya destrucción parcial tuvo lugar con el trascurso de una de las batallas.

Es cierto que lo que resta de este primer intento de integración son piedras que ya no reflejan el poder que representaba la civilización ind'́gena. El desembargador gaúcho Ruy Ruben Ruschel, ya fallecido, en una ocasión dijo que "toda aquella brillante civilización finalmente se convirtió en estos escombros, en estas ruinas a las que admiran los turistas de hoy, a veces sin entender" ". En su época han alcanzado un extraordinario desarrollo en términos de bienestar material, normas morales y calidad de vida ${ }^{7}$, según Antonio Carlos Wolkmer, profesor de Historia del Derecho del curso de posgrado en Derecho de la Universidad Federal de Santa Catarina, que duró aproximadamente doscientos cincuenta años.

La conquista, la superioridad militar de los conquistadores, las enfermedades y epidemias introducidas por los europeos, las rivalidades internas de las civilizaciones, la pérdida de la propiedad indígena con la firma del Tratado de Madrid, las guerras guaraníticas entre 1754 y 1756 y la expulsión de los jesuitas en 1767 han contribuido a la desintegración de los pueblos indígenas.

Sin embargo, otros factores han contribuido asimismo a la disolución de la sociedad guaraní, principalmente las guerras desencadenadas con los movimientos independentistas de los principales países de América del Sur.

Los movimientos independentistas de América, de los que surge clara la figura de

\footnotetext{
${ }^{5}$ Sepé Tiaraju tombou há 243 anos. Correio do Povo. Porto Alegre, 7 feb, 1999, p. 15.

"RUSCHEL, R. R. Op, cit, p. 196.

${ }^{7}$ WOLKMER, A. C. (1998), "Pluralidade jurídica na América luso-hispânica", en: WOLKMER, Antônio Carlos forg.). Direito e justiça na América indígena: da conquista à colonização. Porto Alegre, Livraria do Advogado, p. 85 .
} 
Simón Bolívar como el gran ideólogo de una Confederación de Estados Americanos Independientes, fijaron fronteras, acabando así con la libertad de ir y venir que tenían los indios. En ese sentido, ha contribuido también al ocaso de las reducciones la colonización europea blanca, latifundiaria, que le relegó al indio a la condición de humilde peón de estancia o de proletario de la tierra ${ }^{8}$ al haberlo despojado hasta de la religión, su base de vida.

Fracasa de este modo, con los pueblos guaraníes diezmados, el primer intento de integración regional, que había contado con el auxilio de los jesuitas. "El período de más de cien años en que éstos actuaron en la cuenca del Plata es un ejemplo de integración regional que funcionó de forma efectiva, pese a las inevitables miserias humanas".

En las plazas de muchas ciudades de Rio Grande do Sul hay monumentos que reflejan lo que representó la presencia indígena en esa región de América.

\section{EL SURGIMIENTO DEL MERCOSUR}

Visto y analizado este período de la historia, se observa que es recién dos siglos tras la expulsión de los jesuitas que surge en América otra propuesta de integración, dirigida por la Comisión Económica para América Latina y Caribe, la CEPAL, organismo de la ONU. Esta propuesta ha representado el reflejo de los sucesos europeos de posguerra, que en ese continente han hecho surgir la Comunidad Económica Europea, hoy la Unión Europea, el bloque económico más adelantado y prometedor del que se tiene conocimiento. Posteriormente, como resultado de los estudios de la CEPAL, surge en América la Asociación Latinoamericana de Libre Comercio, ALALC, la primera gran iniciativa con miras al aumento de la actividad comercial interbloque en esta región del mundo.

Sin embargo la instauración de gobiernos dictatoriales en la mayoría de sus países miembros, la condición que impide la libre circulación de bienes, personas y mercancías impuesta por dichos regímenes, la ausencia de voluntad política de los gobiernos de aquel entonces, la creciente deuda externa de los países sudamericanos y la inexistencia de un órgano de carácter supranacional fueron factores que han determinado el fracaso de la ALALC.

En reemplazo de esa Asociación los mismos doce países que la integraban formaron otra, la Asociación Latinoamericana de Integración, ALADI, ya en la década de los ochenta, por medio de la firma del Tratado de Montevideo de 1980. Dicha asociación se vio posteriormente sometida a los mismos problemas y al desinterés anteriormente señalados, sumados al surgimiento de otros procesos de integración como el Pacto Andino y el propio

\footnotetext{
${ }^{8}$ RUSCHEL, R. R. (1998), "O direito de propriedade dos índios missioneiros", en: WOLKMER, Antônio Carlos. Direito e justiça na América indígena: da conquista à colonização. Porto Alegre, Livraria do Advogado, p. 108.

${ }^{9}$ GÁLVEZ, L. Op. cir., p. .59.
} 
MERCOSUR. La ALADI existe todavía y es el centro de los recientes problemas aduaneros entre Brasil y Argentina reseñados por prensa de ambos países.

El fracaso de estas asociaciones sólo se ha revertido con la celebración de una serie de acuerdos bilaterales entre Brasil y Argentina en 1988, que culminaron con la firma del Tratado de Asunción el 26 de marzo de 1991, por el que se instituye el Mercado Común del Sur (MERCOSUR).

\section{CONSIDERACIÓN FINAL}

Tras la experiencia interrumpida de integración Simón Bolívar inició otra. Esta, a su vez, después de verse jaqueada por la Guerra del Paraguay y por la Guerra del Chaco y por distintas desavenencias más próximas en el tiempo con nuestros vecinos, recién ahora - con el esfuerzo de Brasil y de Argentina de la última década - se está consolidando bajo el nombre de MERCOSUR, un fururo mercado común instituido por el Tratado de Asunción de 1991. Es importante destacar que, independientemente de si fueron los indios o el idealista revolucionario Simón Bolívar los pioneros de un proceso de integración en América, es cierto que el modelo que hoy se presenta para la integración de los pueblos en muchos lugares del mundo es fruto de un pensamiento que comenzó con el fin de la Segunda Guerra Mundial, episodio que demostró la fragilidad del sistema vigente entonces para la búsqueda de objetivos como la paz entre los hombres.

\section{BIBLIOGRAFIA}

BRUXEL, Arnaldo. (1978), Os trinta povos guaranis. Caxias do Sul (UCS) - Porto Alegre, Sulina, 162p.

CLEMENTI, Hebe (comp.). (1997), La dimensión cultural del Mercasur. Buenos Aires, UBA, 103p.

GÁLVEZ, Lucía. (1997). "Las misiones jesúticas entre los guaraníes: primer intento de integración regional", en: CLEMENTI, Hebe (comp.). (1997), La dimensiont cultural del MERCOSUR Buenos Aires, UBA, p.45-59.

RUSCHEL, Ruy Ruben. (1998). "O direito de propriedade dos índios missioneiros", en: WOLKMER, Antônio Carlos (org.). (1998). Direito e justifa na América indigena: da conquista à colonização. Porto Alegre, Livraria do advogado, p. 95-109.

. (1998), "Sistema jurídico dos povos missioneiros", en: WOLKMER,

Antônio Carlos (org.). (1998). Direito e justifa na América indígena: da conquista à colonização. Porto Alegre, Livraria do advogado, p. 183-197.

SEPÉ Tiaraju tombou há 243 anos. Correio do Powr. Porto Alegre, 7 de feb. 1999, p. 15.

WOLKMER, Antônio Carlos (org.). (1998). Direito e justíga na América indigena: da conquista à colonização. Porto Alegre, Livraria do Advogado, 242p.

. (1998), "Pluralidade jurídica na América luso-hispânica", en: WOLKMER, Antônio Carlos (org.). (1998). Direito e justifa na América indígena: da conquista à colonização. Porto Alegre, Livraria do advogado, p. 75-93. 